\title{
Enhanced interaction between natural killer cells and lung cancer cells: involvement in gefitinib-mediated immunoregulation
}

Sisi He ${ }^{\dagger}$, Tao Yin ${ }^{\dagger}$, Dan Li, Xiang Gao, Yang Wan, Xuelei Ma, Tinghong Ye, Fuchun Guo, Jianhong Sun, Ziqiang Lin and Yongsheng Wang ${ }^{*}$

\begin{abstract}
Background: Natural killer (NK) cells can kill tumor cells in a non-MHC-restricted manner. However, cancer cells frequently escape from the attack of NK cells by multiple ways. In this study, we investigated the effect of gefitinib on the interaction between NK cells and lung cancer cells.

Methods: ${ }^{51} \mathrm{Cr}$ release assay, CD107a assay, and IFN- $\gamma$ secretion assay were performed to detect the sensitivity of lung cancer cell lines A549 and H1975 to NK cells cytotoxicity in the presence of gefitinib. Human NK cells were co-cultured with A549 and H1975 cell lines in the presence of gefitinib. NKG2D ligands, ULBP1, ULBP2, MICA, and MHC-I on tumor cells, and NKG2D, NKp44 and NKp46 on NK cells were evaluated with flow cytometry. ${ }^{51} \mathrm{Cr}$ release assay was performed when NKG2D antibody were added into the co-culture system. Expressions of stat3 and LC3 I/II on tumor cells were determined with western blot after co-cultured with NK cells. After treated with gefitinib, mannose-6-phosphate receptor (MPR) on H1975 cells was evaluated by flow cytometry. ${ }^{51} \mathrm{Cr}$ release assay were performed when MPR antagonist were used.

Results: Gefitinib increased cytotoxicity of NK cells to human lung cancer H1975 cells with EGFR L858R + T790M mutations, while not in A549 cells with wild type EGFR. Gefitinib could block the immune escape by up-regulating the expression of NKG2D ligands ULBP1, ULBP2 or MICA on tumor cells and NKG2D on NK cells in the co-culture system. Gefitinib and NK cells up-regulated MHC-I expression in A549 while not in H1975 cells. NKG2D antibody blocked the enhanced NK cytotoxicity by gefitinib. The combination of NK cells and gefitinib could significantly down-regulate stat3 expression. Furthermore, NK cells-mediated tumor cell autophagy was observed in A549 cells while not in H1975 cells. Notably, gefitinib increased autophagy and MPR expression in H1975 cells, which improved the sensitivity to NK cell-based immunotherapy.
\end{abstract}

Conclusions: Gefitinib greatly enhanced NK cell cytotoxicity to lung cancer cells with EGFR L858R + T790M resistance mutation. Combination of EGFR tyrokinase inhibitors and NK cells adoptive immunotherapy may represent a potentially effective strategy for patients with non-small cell lung cancer.

Keywords: Gefitinib, Natural killer cells, Immunotherapy, EGFR, NSCLC

\footnotetext{
* Correspondence: wangys75@gmail.com

${ }^{\dagger}$ Equal contributors

Department of Thoracic Oncology, Cancer Center, State Key Laboratory of Biotherapy, West China Hospital, Sichuan University, Chengdu 610041, PR China
} 


\section{Background}

Lung cancer is a leading cancer death worldwide [1]. The use of selectively targeted agents has revolutionized the treatment of lung cancer and shown promising clinical activity. EGFR is frequently over-expressed in nonsmall cell lung cancers (NSCLC) [2]. As the first small inhibitor for EGFR, gefitinib induce dramatic clinical responses and improve progression-free survival, through inhibition of EGFR-driven signals for tumor cells survival and proliferation [3]. However, many cancer patients invariably develop drug resistance [4-6]. The secondary T790M mutation within the EGFR kinase domain is a major mechanism of acquired resistance to EGFR tyrosine kinase inhibitors (TKI) in NSCLC [7]. However, clinical response to gefitinib has been demonstrated to be not correlated with EGFR levels, and several other molecular mechanisms are also important in predicting clinical response $[8,9]$.

NK cells are key components of innate immunity and participate in immunity against virus-infected and neoplastic cells [10]. NK cell-based immunotherapy may be an efficient way to eliminate tumor cells, and many clinical trials have been conducted and showed benefit [11]. NK cell can kill many cancer cells via direct killing, induction of apoptosis or IFN- $\gamma$ secretion [12,13]. Furthermore, NK cells can inhibit tumor cell metastasis [14]. Several activating receptors on NK cell surface have been discovered, which are dispensable for NK cell activation $[15,16]$. The major receptors responsible for NK cells activation are NKG2D and natural cytotoxicity receptors (NCRs; that is, NKp30, NKp44 and NKp46) [17]. NKG2D is the main activating receptor, and the binding to its ligand can promote NK cells cytotoxic lysis of target cells. Engagement of NKG2D activates NK cells and then become a promising anti-cancer strategy $[18,19]$. MHC class I chain-related molecules, MICA and MICB, and the UL16-binding proteins, ULBP-1, ULBP-2, and ULBP-3 are the main ligands for human NKG2D, which expressed on many cancer cells and infected cells [20,21]. Several clinical interventions have been demonstrated to up-regulate NKG2D ligands expression on tumor cells and enhance susceptibility to NK cells, including chemotherapy, radiotherapy and HDAC-1 [22], Proteasome inhibitor [23].

However, several factors limited the efficiency of NK cells adoptive therapy. Except for its poor ability to home to tumor area, tumor microenvironment edited NK cells and changed NK cell response [24-26]. Recent reports showed that melanoma cells inhibited the expression of NK receptors and impaired NK cells cytolytic functions [27]. NK cells per se can induce target cell autophagy and enhance cancer cell survival [28]. Those results suggested that immunosuppressive barriers developed by tumor cells could impair NK cells based immunotherapy.
Several immunomodulatory approaches have been investigated to enhance anti-tumor therapy efficiency. Imatinib potentiates antitumor $\mathrm{T}$ cell responses through the inhibition of IDO [29]. Imatinib can act on host DCs to promote NK cell activation [30]. In the present study, we examine how gefitinib modulate the tumor cells and NK cells after short-term interactions. We here show that gefitinib enhance NK cells and tumor cells interaction by modulation of NKG2D ligands and NKG2D and improve anti-tumor NK response. Gefitinib can reduce stat3 expression in tumor cells. MPR expressioninduced by gefitinib can facilitate NK cell cytotoxicity in human lung cancer cells with EGFR L858R + T790M resistance mutation. Our results suggest that making use of immunoregulatory property of gefitinib may be a potential new therapeutical option for lung cancer with EGFR L858 + T790M resistance mutation.

\section{Materials and methods Cell culture}

Human NSCLC cell lines A549 and H1975 were obtained from American Type Culture Collection (ATCC; Manassas, VA) and maintained in RPMI 1640 media (Hyclone) supplemented with 10\% FBS (GIBCO). NK cells were obtained from peripheral blood of different health donors by magnetic bead isolation using NK isolation kit (R\&D systems) according to the manufacturer's instructions. NK cell purity was $>85 \%$. All of the researches were performed in accordance with the Sichuan University's Ethics Committees. NK cells were maintained in RPMI 1640 media supplemented with $200 \mathrm{U} / \mathrm{ml} \mathrm{IL-2}$ and $10 \mathrm{ng} / \mathrm{ml} \mathrm{IL-15}$ and 10\% FBS.

\section{Flow cytometry}

Primary NK cells were stained with CD56 (R\&D systems) and CD3 antibodies (BD Pharmingen). Cells were acquired on a FACSCalibur flow cytometer and data were analyzed using Cell Quest software (BD Biosciences). NK cells were co-cultured with the indicated target cells in a ratio of 1:1 in 24-well plates for 24 hours, and $5 \mu \mathrm{g} / \mathrm{ml}$ gefitinib (Astra Zeneca) was added into co-culture system for another 24 hours. Afterward, NK cells were collected and examined for the expression of NKG2D, NKp44, and NKp46. ULBP1, ULBP2, MICA expression were evaluated on tumor cells. Intracellular IFN- $\gamma$ staining was performed after fixation in $2 \%$ paraformaldehyde and permeabilization in 1\% Trixton. IFN$\gamma$-PE antibody was purchased from BD Pharmingen. Antibodies against NKG2D, NKp44, NKp46, ULBP1, ULBP2, MICA were purchased from R\&D systems. For MPR expression, H1975 tumor cells were treated with gefitinib for 48 hours, and then the MPR levels on cell surface was evaluated by flowcytometry. 


\section{CD107a assays}

NK cells were co-cultured with the indicated target cells in a ratio of 1:1 in the presence CD107a antibody (R\&D systems) for $4 \mathrm{~h}$ in the presence or absence of $5 \mu \mathrm{g} / \mathrm{ml}$ gefitinib. Afterward, cells were washed and CD107a levels on the NK cells were then analyzed by flow cytometry.

\section{Western blot}

Tumor cells were harvested and lysed in radioimmunoprecipitation buffer for $30 \mathrm{~min}$. Protein concentration was determined by Bradford assay. Cell lysates were resolved by SDS-PAGE, and transferred to PVDF membrane (Millipore). Membrane was blocked in 5\% non-fat milk and then blots were probed with antibodies for stat3 and LC3 (Cell Signaling Technology) respectively. After incubated with horseradish peroxidaseconjugated secondary antibodies, probes were visualized by a chemiluminescent detection system. GAPDH as a loading control. Antibody against GAPDH was obtained from Cell Signaling Technology.

\section{${ }^{51} \mathrm{Cr}$ release assay}

Target cells were labeled with $1 \mathrm{mCi}$ of $\mathrm{Na}_{2}{ }^{51} \mathrm{CrO}_{4}$ for $1 \mathrm{~h}$ at $37^{\circ} \mathrm{C}$. Cells were then washed three times with complete medium and incubated with effector cells at different $\mathrm{E}: \mathrm{T}$ ratios in the presence or absence of $5 \mu \mathrm{g} / \mathrm{ml}$ gefitinib. After incubation for $4 \mathrm{~h}$ at $37^{\circ} \mathrm{C}$, cell free supernatants were collected and counted on scintillation counter. Percentage of cytolysis was calculated by (sample release-spontaneous release)/(maximum release-spontaneous release). To block the cytotoxicity of NK cells, mannose-6-phosphate or $20 \mu \mathrm{g} / \mathrm{mL}$ NKG2D antibody ( $R \& D$ system) were added into the ${ }^{51} \mathrm{Cr}$ release assay system.

\section{Statistical analyses}

ANOVA was used to identify significant group differences. $p<0.05$ was considered statistically significant.

\section{Results}

Gefitinib enhanced cytotoxicity of NK cells in human lung cancer cells with EGFR L858R + T790M mutation

To investigate whether gefitinib could increase the susceptibility of NSCLC cell lines to cytolytic activity of NK cells, ${ }^{51} \mathrm{Cr}$ releasing assay was performed. Two gefitinib resistance NSCLC cell lines A549 (EGFR wt) and H1975 (EGFR L858R + T790M) were used. In the presence of gefitinib, A549 showed some more enhanced susceptibility to NK cells cytotxicity; however, there were no significant difference (Figure 1A). As to H1975 with L858R + T790M, gefitinib significantly improved NK cells cytotxicity (Figure 1B). Those results suggested that gefitinib enhanced cytotoxicity of NK cells to human lung cancer with EGFR L858R + T790M.

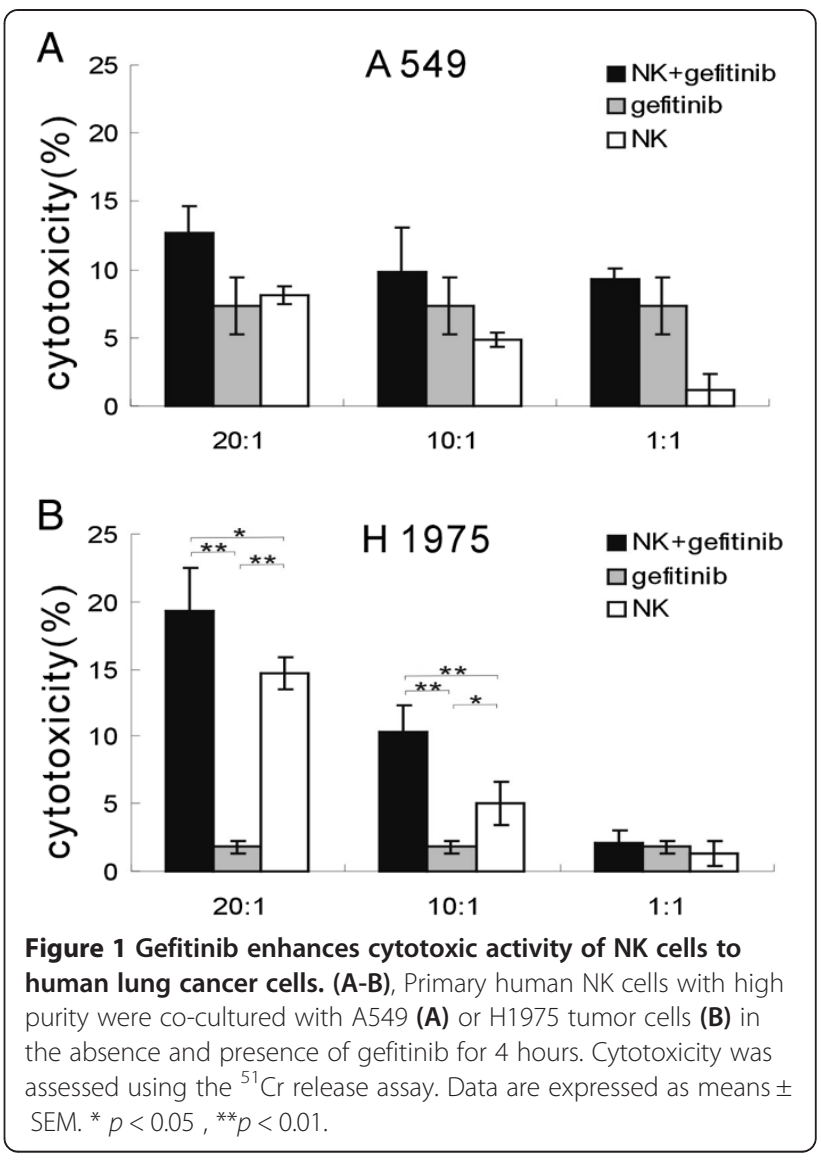

Degranulation of NK cells triggered by gefitinib

CD107a degranulation was correlated with NK and T cell killing [31]. The function of NK cells was evaluated by measuring degranulation on the basis of CD107a staining. In the presence of gefitinib, NK cells coincubated with H1975 degranulated more than did NK cells from control group (Figure 2E-F). However, there was no significant improvement in A549 cells (Figure 2C-D). Our results suggested that gefitinib could enhance the ability of NK cell degradulation to lung cancer cells with EGFR L858R + T790M.

\section{Role of IFN- $\gamma$ in the immunomodulation of gefitinib}

IFN- $\gamma$ has been demonstrated to be an important effector cytokine produced by NK cells, which plays an essential role in response to infection and tumors [32]. To determine whether gefitinib enhancement of NK cell cytotoxicity was partially attributed to IFN- $\gamma$, we then evaluated IFN- $\gamma$ expression by NK cells. There were no any improvements in IFN- $\gamma$ secretion in A549 cells (Figure 3C-D). H1975 tumor cells inhibited IFN$\gamma$ secretion from the NK cells (Figure 3E). However, gefitinib significantly attenuated the inhibitory effect of H1975 cells on NK cells IFN- $\gamma$ secretion by after 24 hours stimulation (Figure $3 \mathrm{~F}$ ). 


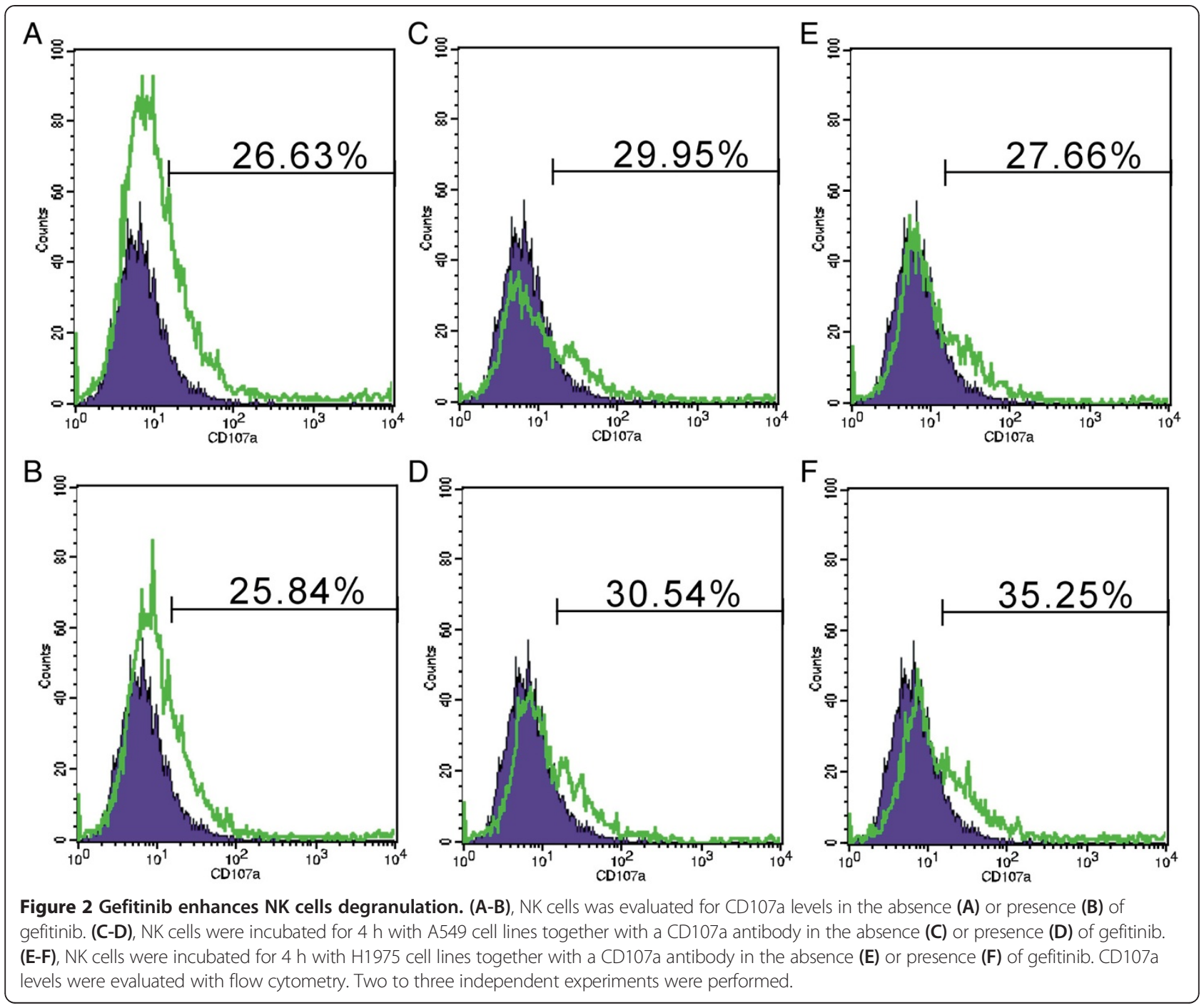

Gefitinib restore receptor-ligand interactions between NK cells and human lung cancer cells

Tumor cells impair NK cell-mediated killing by decreasing expression of surface ligands for NK cell activating receptors, which include NKG2D and NCRs [33,34]. To investigate whether gefitinib could up-regulate surface ligands for NK cell activating receptors, we co-cultured two human lung cancer cell lines with NK cells and evaluated the expression of ULBP1, ULBP2 and MICA by flowcytometry. ULBP1, ULBP2 and MICA were downregulated after co-culture of NK cells and H1975 cell line (Figure 4B). In A549, ULBP2 and MICA expression were down-regulated (Figure 4A). Those results suggested that human lung cancer cells could decrease expression of surface ligands for NKG2D. However, once gefitinib was administered, ULBP1, ULBP2 and MICA were all up-regulated in A549 cells (Figure 4A). In the H1975 cell line, gefitinib could only up-regulate ULBP1 expression (Figure 4B). Our resultes suggested that gefitinib could partially increase expression of surface ligands for NKG2D and enhance immune recognition of cancer cells by NK cells.

To investigate whether gefitinib influence the MHC-I expression during the short interaction between NK cells and tumor cells, we evaluated the MHC-I levels on tumor cells. In A549 cell line, gefitinib and NK strikingly up-regulated the MHC-I expression (Figure 5), while the expression of MHC-I was slightly down-regulated in H1975 cell line (Figure 5). Collectively, these results suggested that gefitinib and NK cells could upregulate the MHC-I in human lung cells with wild type EGFR, while not significantly influence the MHC-I expression on human lung cells with wild type EGFR L858R + T790M.

On the other side, to investigate whether gefitinib could affect NCRs and NKG2D expression on NK cells, we detected NCRs and NKG2D expression by flow cytometry. NCRs had no significant changes; however, we 


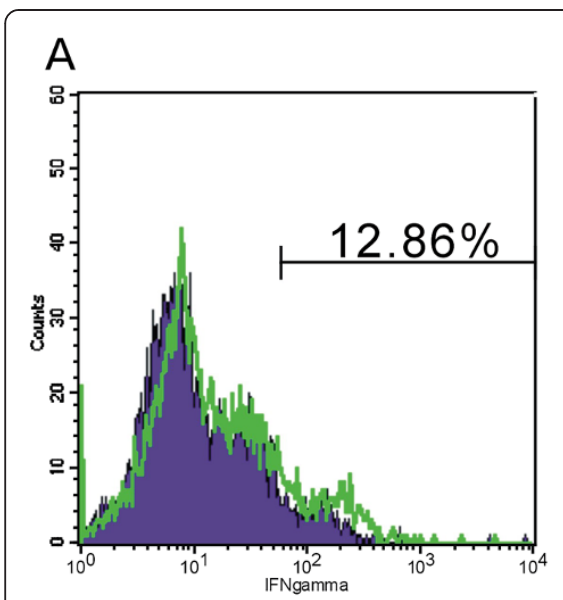

B

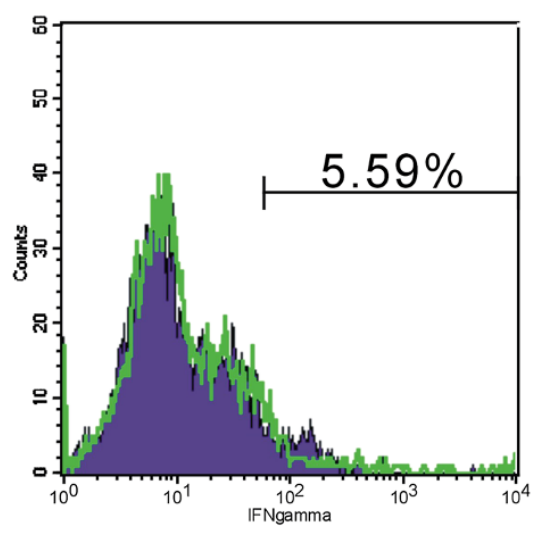

C

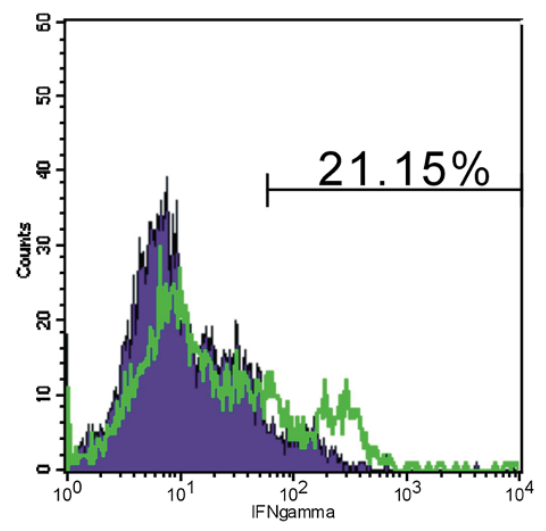

D

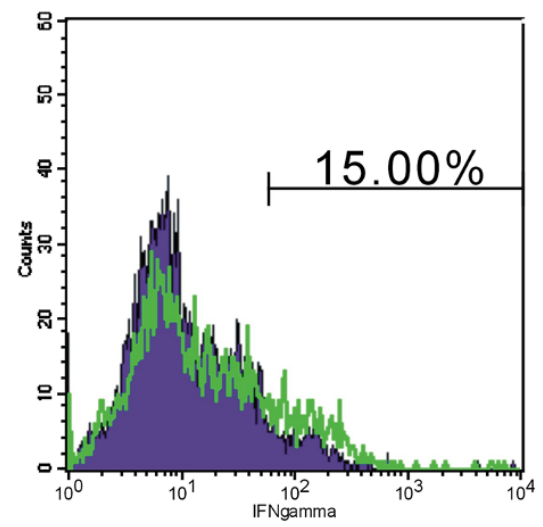

E

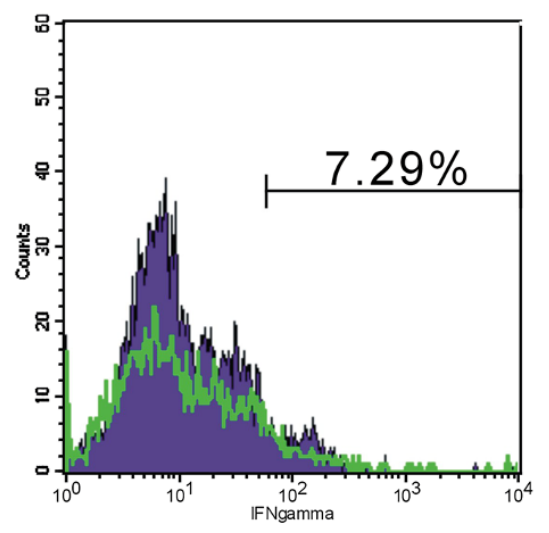

$\mathrm{F}$

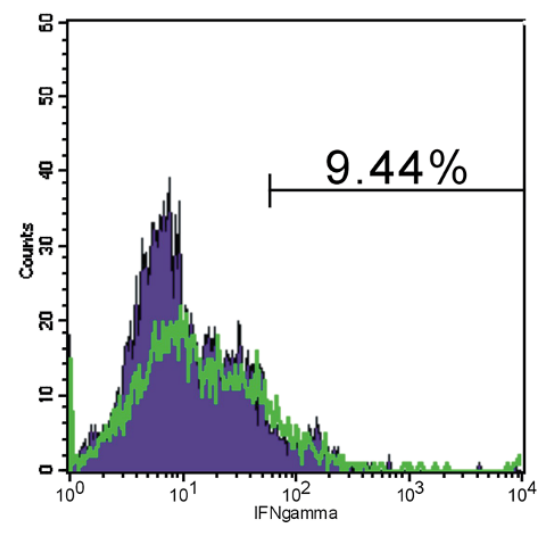

Figure $\mathbf{3}$ Gefitinib increases IFN- $\boldsymbol{\gamma}$ production of NK cells. (A-B), NK cells was evaluated for the IFN- $\boldsymbol{\gamma}$ secretion in the absence (A) or presence (B) of gefitinib. (C-D), NK cells were incubated with A549 cell lines in the absence (C) or presence (D) of gefitinib. (E-F), NK cells were incubated with $\mathrm{H} 1975$ cell lines in the absence $(\mathbf{E})$ or presence (F) of gefitinib. Intracellular IFN- $\gamma$ levels were evaluated with flow cytometry. Two independent experiments were performed.

found that in the presence of gefitinib, NKG2D was significantly up-regulated, especially after co-cultured with H1975 tumor cells (Figure 6A). To evaluate whether NKG2D mediated the enhanced cytotoxicity of NK cells by gefitinib, NKG2D antibody was added into the coculture system. ${ }^{51} \mathrm{Cr}$ release assay showed that NKG2D antibody significantly blocked the enhanced cytotoxicity of NK cells by gefitinib (Figure 6B).

\section{Role of stat3 in the immunomodulation of gefitinib}

Activation of Stat3 has been demonstrated in a variety of tumors. Stat3 can be phosphorylated by activated EGFR and promote tumor survival in vivo in NSCLC [35]. Stat3 is a key factor in gefitinib-resistant EGFR T790M cells [36]. Recent reports have demonstrated that Stat3 exerts an inhibitory effect on antitumor NK cell immunity [37]. To determine if gefitinib reversal of tumor cells mediated inhibition of NK cell activation was associated with the inhibition of stat3, we quantified the expression of stat3 in the tumor cells with western blot. As expected, gefitinib treatment alone for 24 hours substantially decreases stat3 expression (Figure 7A). Combination of gefitinib with NK cells can further down-regulate stat3 in H1975 cells (Figure 7A).

\section{MPR expression-induced by gefitinib enhanced the NK cytotoxity}

Although gefitinib could restore NKG2D receptor-ligand interactions between NK cells and human lung cancer cells, and inhibit stat3 expression, further molecular mechanisms should be investigated on the difference between A549 and H1975 to the sensitivity to gefitinibmediated NK cells response. Recent report suggested that autophagy induced by conventional chemotherapy could mediate tumor cell sensitivity to immunotherapy [38]. To test whether the response difference was caused by autophagy, autophagic marker LC3 was evaluated. We found that gefitinib could increase autophagy in H1975, as demonstrated by the enhanced conversion of LC3-I to LC3-II (Figure 7A), While there was no 


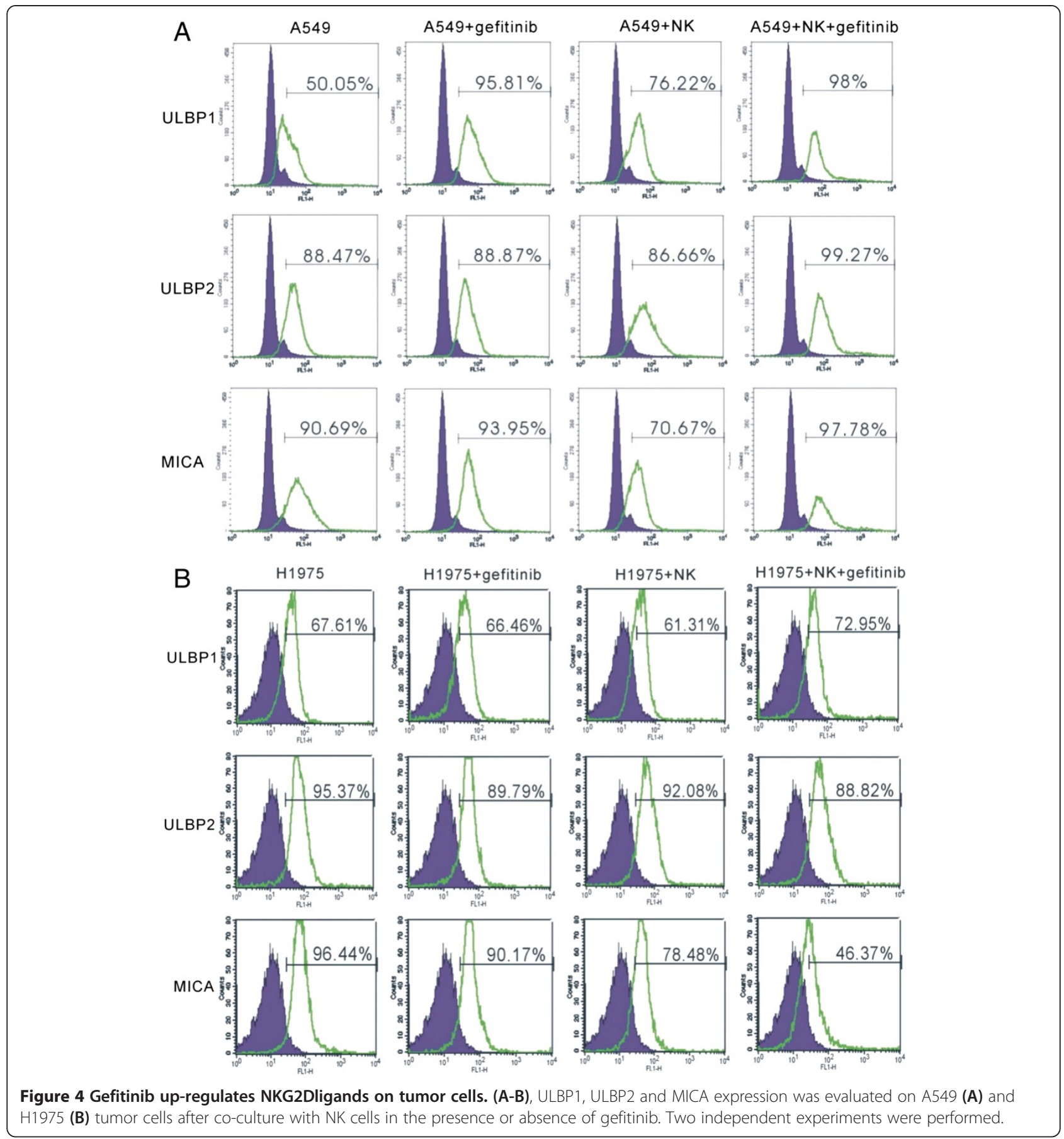

obvious autophagy in A549 (Figure 7A). Interestingly, we also found that NK cells per se induced autophagy in A549 cells, while not in H1975 cells (Figure 7A).

Autophagy can induce mannose-6-phosphate receptor expression in murine tumor cells [38]. To test whether gefitinib-induced autophagy can up-regulate MPR expression on human tumor cells, we treated H1975 cells for 48 hours with gefitinib and the analyzed the cell membrane MPR expression by flow cytometry. We found that
MPR expression was obviously up-regulated after gefitinib treatment (Figure 7B). Then, we further investigated whether gefitinib-induced MPR expression could enhance the cytotoxicity of NK cells. We used MPR antagonist mannose-6-phosphate to block MPR and performed the ${ }^{51} \mathrm{Cr}$ releasing assay. MPR blockade significantly impaired the cytotoxic function of NK cells (Figure 7C). Together, these results suggested that MPR expression-induced by gefitinib could enhance the NK cytotoxity. 

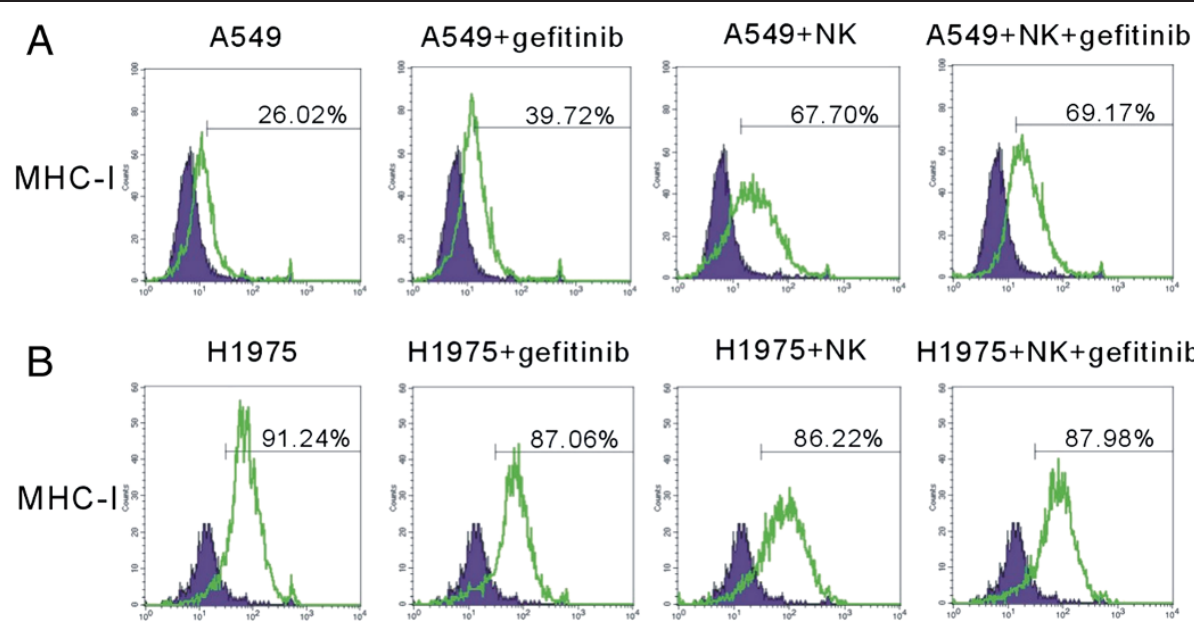

Figure 5 Gefitinib changes MHC-I expression on tumor cells. (A-B), MHC-I expression was evaluated on A549 (A) and H1975 (B) tumor cells after co-culture with NK cells in the presence or absence of gefitinib. Two independent experiments were performed.

\section{Discussion}

Reasons for the failure of immune cell based therapy have been advanced [39]. Tumor cells can employ a variety of mechanisms to evade immune surveillance. In our short-term co-culture system, A549 and H1975 lung cancer cells down-regulated surface expression of NKG2D ligands ULBP1, ULBP2 and MICA following co-culture with NK cells. Those ligands facilitate NK cells recognition of tumor cells and render tumor cells susceptible to NK cell-mediated cytolysis [40]. Down regulation of those ligands may help to evade NKG2Dmediated immunosurveillance. NKG2D ligands may represent a potential target for evoking the innate immune response against tumors. Approaches to activate NK cells by up-regulating of NKG2D ligands on tumor cells have been investigated. Our present study and those of others showed that geftinib can partially up-regulate NKG2D ligands ULBP1, ULBP2 or MICA on tumor cells [34]. We also found gefitinib or NK cells could enhance MHC-I expression, which impairs the recognization of NK cells, in lung tumor cells with wild type EGFR, while not in those with EGFR L858R + T790M. NKG2D is the main activation receptor that potently stimulates cytotoxicity and production of IFN- $\gamma$ by NK cells [41].

Lymphocyte activation integrates multiple signals. NK cells express a plethora of cell surface markers belonging to the TNFR family, such as CD27, CD137 (4-1BB), CD134 (OX40) and glucocorticoid-induced TNFR (GITR), which play important roles in immune synapses [42]. CD137-specific agonist antibodys increase trastuzumabmediated NK cell cytotoxicity and enhance trastuzumab efficacy against human breast cancer [43]. The other known activating NK cell receptors include NKG2D, NCRs, 2B4, NTB-A and NKp80, CS1 [44] and the leukocyte adhesion molecule DNAM-1 [45]. Here, we focus our study on NKG2D and NCRs, which are recognized as the main triggering receptors of NK cells that are involved in target cell lysis. NCRs recognizes yet uncharacterized ligands on tumor cells. We here found the gefitinib up-regulated markedly NKG2D levels on human NK cells in the co-culture of human H1975 lung cancer cells, while NKp44 and NKp46 expression was less influenced. NKG2D plays an important role in immunosurveillance. Aberrant loss of NKG2D in cancer is a important mechanism of immune evasion. Reduced expression of NKG2D on NK and T cells of cancer patients has been reported $[40,46]$. We then examined NKG2D expression on NK cells and found that geftinib up-regulated NKG2D expression on NK cells, and we further found that the enhanced NK cytotoxicity by gefitinib was mediated by NKG2D. The functional relevance of restoration of NKG2D-NKG2DL interaction by gefitinib was demonstrated by the enhanced cytotoxicity, degranulation and IFN- $\gamma$ production of NK cells in response to lung cancer cells with EGFR L858R + T790M resistance mutation.

Recently, immune system has been demonstrated to contribute substantially to the antitumor effects of small molecule inhibitors. Through the inhibition of IDO, imatinib potentiates antitumor $\mathrm{T}$ cell responses in gastrointestinal stromal tumor [29]. Imatinib can also act on host DCs to promote NK cell activation [30]. In our present work, we find that, beyond its EGFR tyrokinase inhibitory effect, gefitinib also has immunomodulatory effect in gefitinib-resistance cell lines, which can enhance immune recognization of tumor cells by NK cells and attenuate the inhibitory effect of tumor cells on NK cells.

One of the major reasons for the weak effect of cell based immunotherapy is thought to be immunosuppression. Tumor microenvironment, with abundant of 

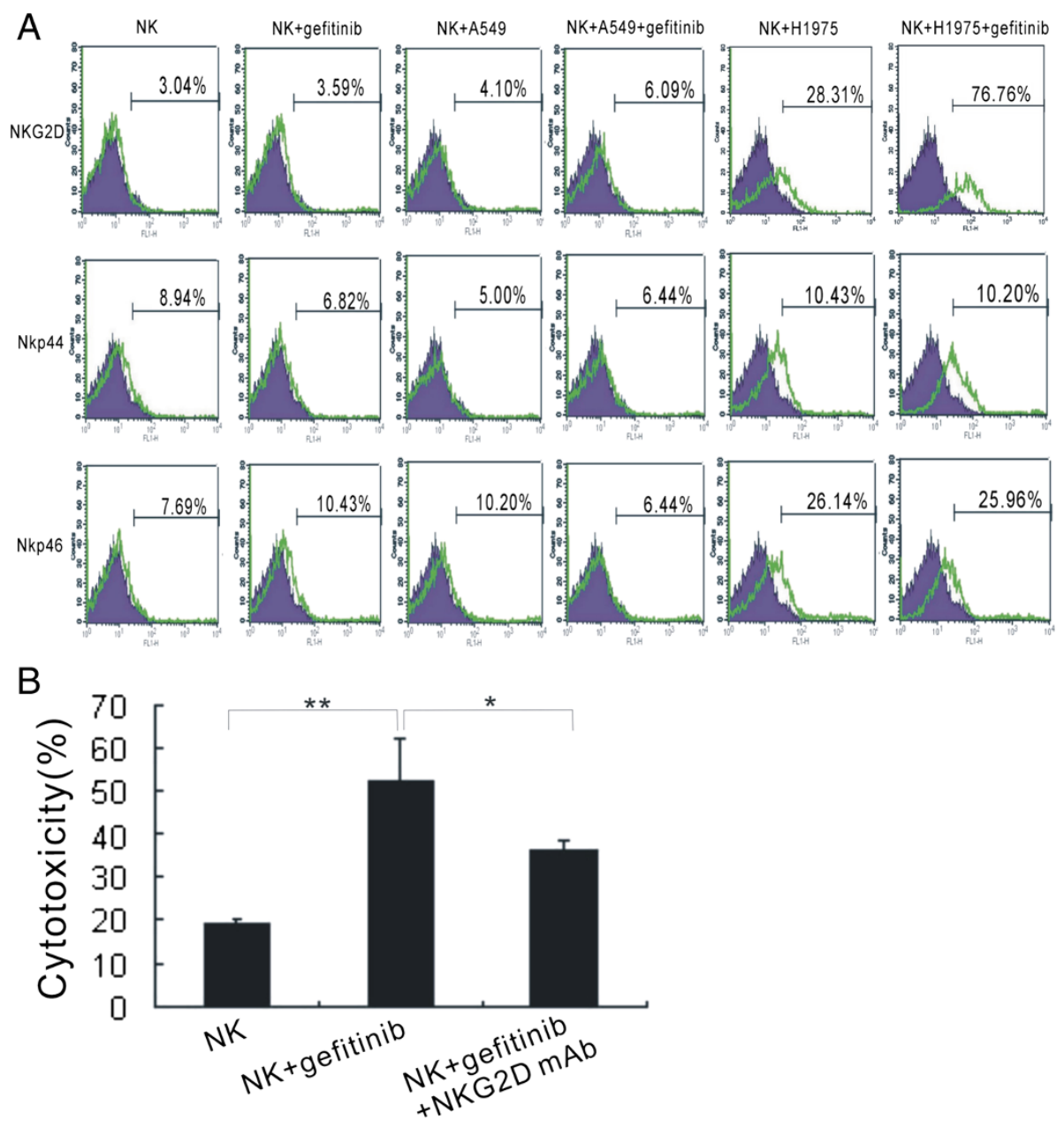

Figure 6 Gefitinib enhances NK cells cytotoxicity via NKG2D. (A) Gefitinib up-regulated NKG2D on NK cells. NKG2D, NKp44 and NKp46 expression was examined on NK cells following co-culture with A549 and H1975 tumor cells. Three independent experiments were performed. (B) NKG2D antibody blocked the enhanced NK cells cytotoxicity by gefitinib. The concentration of NKG2D antibody was $20 \mu \mathrm{g} / \mathrm{mL}$. ${ }^{*} p<0.05$, ${ }^{* *} p<0.01$.

immunosuppressive cells and molecules, can inhibit effector cells and result in insufficient antitumor effects [24-26]. Stat3 plays an important role in the process in tumor immunosuppression. Activation of IL-6R/ JAK1/STAT3 signaling can induce de novo resistance in NSCLC with T790M resistance mutation [47]. Activation of stat3 has been demonstrated to lead to the production of multiple immunosuppressive cytokines [48]. Stat3 exerts an inhibitory effect on antitumor NK cell immunity, and Stat3 knockdown decreases MHC class I expression on lung tumor cells and results in the activation of NK cell-mediated cytotoxicity [37]. We found that gefitinib could inhibit stat3 expression in lung cancer cells. Furthermore, combination of gefitinib and NK cells can further reduce stat 3 expression. We postulate that the attenuation of inhibitory effect of tumor cells on NK cells may partially attributed to the stat3 inhibition by gefitinib.
In our present study, we also find that high purity NK cells increase autophagy in A549 cancer cells with wide type EGFR, while not in H1975 cells with EGFR L858R + T790M. Lymphocyte provides lytic signals to tumor cells, and they also promote autophagy in the remaining tumor cells. These processes are primarily mediated by NK cells [28]. Cell-mediated autophagy promotes cancer cell survival and induces resistance to subsequent therapies [28]. NK cell-induced autophagic change may promote cancer cells survival. From the perspective of view, NK cells therapy alone may not be an effective strategy. Though gefitinib can also restore NKG2D ligands and NKG2D interaction, and inhibit stat 3 expression, we did not find significant improvement on NK cells cytotoxicity to A549 cells with wild type EGFR, while there was significant enhancement to H1975 cells with EGFR L858R + T790M resistance mutations. The elevated MHC-I expression induced by gefitinib or NK cells may block 

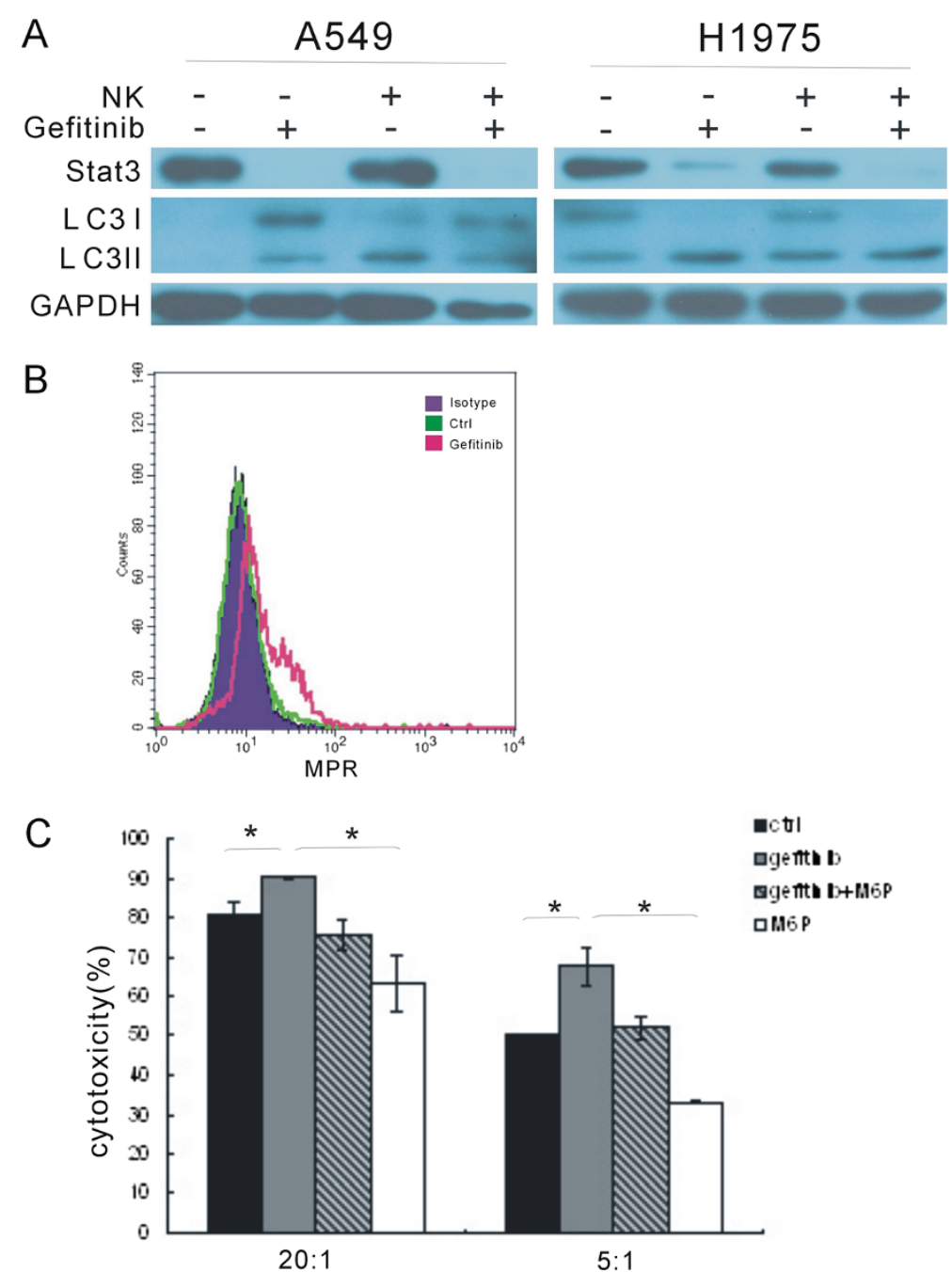

Figure 7 Stat3, autophagy and MPR expression are engaged in the immunoregulation of gefitinib. (A), after co-culture with NK cells in the presence or absence of gefitinib, A549 and H1975 cells were evaluated for stat3 expression and LC3 levels with western blot. (B), MPR expression was elevated on H1975 tumor cells treated with gefitinib. (C), MPR antagonist mannose-6-phosphate impaired the cytotoxic function of human NK cells to $\mathrm{H} 1975$ tumor cells treated with gefitinib. Cytotoxicity was assessed with the ${ }^{51} \mathrm{Cr}$ release assay. Data are expressed as means \pm SEM. ${ }^{*} p<0.05$.

the cytotoxicity of NK cells to A549. Recent report suggests that autophagy caused by chemotherapy can improve tumor cell sensitivity to immunotherapy, which is mediated by up-regulating mannose-6-phosphate receptor on the tumor cell surface [38]. We find that gefitinib can enhance autophagy in the cell lines with L858R + T790M and up-regulate the cell surface MPR expression. MPR antagonist mannose-6-phosphate reduces the cytoxicity of NK cells. The enhanced NK cells cytotoxicity by gefitinib may be attributed to elevated MPR expression induced by gefitinib.

\section{Conclusions}

Our present study suggests that gefitinib has multiple effects on the interaction between NK cells and tumor cells. Similar to imatinib, gefitinib has its own immunomodulatory property, which can enhance NK cell cytotoxicity. Gefitinib enhances NKG2D-NKG2D ligands interaction between NK cells and human lung cancer cells. Combination of gefitinib with NK cells downregulates stat3 expression. MPR expression induced by gefitinib facilitates antitumor NK cell immunity. Therapeutic significance of our finding is that administration of gefitinib may offer a novel adjuvant strategy to enhance NK cells based immunotherapy in NSCLC with EGFR L858R + T790M resistance mutation.

\section{Abbreviations}

EGFR: Epithelial growth factor; NK cell: Natural killer cell; TKI: Tyrosine kinase inhibitors; MPR: Mannose-6-phosphate receptor; NSCLC: Non-small cell lung cancers. 


\section{Competing interests}

The authors declare that they have no competing interests.

\section{Authors' contributions}

Conception and design: W-YS, H-SS, YT. Development of methodology: W-YS, H-SS, YT, WY. Acquisition of data: H-SS, YT, LD, G-FC, M-XL, Y-TH, S-JH, L-ZQ. Analysis and interpretation of data: W-YS, H-SS, YT, GX, WY. Writing, review, and/or revision of the manuscript: W-YS, H-SS, YT,GX. Administrative, technical, or material support: G-FC, M-XL, Y-TH, S-JH, L-ZQ Study supervision: W-YS, H-SS, YT. All authors read and approved the final manuscript.

\section{Authors' information}

Sisi He and TaoYin are the co-first authors for this paper.

\section{Acknowledgement}

Financial support for this work was provided from National Major Project 2011ZX09302-001-01.

Received: 27 February 2013 Accepted: 6 August 2013

Published: 12 August 2013

\section{References}

1. Kohler BA, Ward E, McCarthy BJ, Schymura MJ, Ries LA, Eheman C, Jemal A Anderson RN, Ajani UA, Edwards BK: Annual report to the nation on the status of cancer, 1975-2007, featuring tumors of the brain and other nervous system. J Natl Cancer Inst 2011, 103:714-736.

2. Tracy S, Mukohara T, Hansen M, Meyerson M, Johnson BE, Janne PA: Gefitinib induces apoptosis in the EGFRL858R non-small-cell lung cancer cell line H3255. Cancer Res 2004, 64:7241-7244.

3. Maemondo M, Inoue A, Kobayashi K, Sugawara S, Oizumi S, Isobe H, Gemma A, Harada M, Yoshizawa H, Kinoshita I, Fujita Y, Okinaga S, Hirano H, Yoshimori K, Harada T, Ogura T, Ando M, Miyazawa H, Tanaka T, Saijo Y, Hagiwara K, Morita S, Nukiwa T: Gefitinib or chemotherapy for non-small -cell lung cancer with mutated EGFR. N Engl J Med 2010, 362:2380-2388.

4. Kwak EL, Sordella R, Bell DW, Godin-Heymann N, Okimoto RA, Brannigan BW, Harris PL, Driscoll DR, Fidias P, Lynch TJ, Rabindran SK, McGinnis JP, Wissner A, Sharma SV, Isselbacher KJ, Settleman J, Haber DA: Irreversible inhibitors of the EGF receptor may circumvent acquired resistance to gefitinib. Proc Natl Acad Sci USA 2005, 102(21):7665-7670.

5. Pao W, Miller V, Zakowski M, Doherty J, Politi K, Sarkaria I, Singh B, Heelan R, Rusch V, Fulton L, Mardis E, Kupfer D, Wilson R, Kris M, Varmus H: EGF receptor gene mutations are common in lung cancers from "never smokers" and are associated with sensitivity of tumors to gefitinib and erlotinib. Proc Natl Acad Sci USA 2004, 101(36):13306-13311.

6. Bean J, Brennan C, Shih JY, Riely G, Viale A, Wang L, Chitale D, Motoi N, Szoke J, Broderick S, Balak M, Chang WC, Yu CJ, Gazdar A, Pass H, Rusch V, Gerald W, Huang SF, Yang PC, Miller V, Ladanyi M, Yang CH, Pao W: MET amplification occurs with or without T790M mutations in EGFR mutant lung tumors with acquired resistance to gefitinib or erlotinib. Proc Natl Acad Sci USA 2007, 104(52):20932-20937.

7. Kosaka T, Yatabe Y, Endoh H, Yoshida K, Hida T, Tsuboi M, Tada H, Kuwano $H$, Mitsudomi T: Analysis of epidermal growth factor receptor gene mutation in patients with non-small cell lung cancer and acquired resistance to gefitinib. Clin Cancer Res 2006, 12:5764-5769.

8. Pedersen MW, Pedersen N, Ottesen LH, Poulsen HS: Differential response to gefitinib of cells expressing normal EGFR and the mutant EGFRvill. Br J Cancer 2005, 93:915-923.

9. Alvarez JV, Greulich H, Sellers WR, Meyerson M, Frank DA: Signal transducer and activator of transcription 3 is required for the oncogenic effects of non-small-cell lung cancer-associated mutations of the epidermal growth factor receptor. Cancer Res 2006, 66(6):3162-3168.

10. Lodoen M, Ogasawara K, Hamerman JA, Arase H, Houchins JP, Mocarski ES, Lanier LL: NKG2D-mediated natural killer cell protection against cytomegalovirus is impaired by viral gp40 modulation of retinoic acid early inducible 1 gene molecules. J Exp Med 2003, 197(10):1245-1253.

11. Leemhuis T, Wells S, Scheffold C, Edinger M, Negrin RS: A phase I trial of autologous cytokine-induced killer cells for the treatment of relapsed Hodgkin disease and non-Hodgkin lymphoma. Biol Blood Marrow Transplant 2005, 11:181-187.

12. Miller JS: The biology of natural killer cells in cancer, infection, and pregnancy. Exp Hematol 2001, 29:1157-1168.
13. Raulet $\mathrm{DH}$, Guerra N: Oncogenic stress sensed by the immune system: role of natural killer cell receptors. Nat Rev Immunol 2009, 9:568-580.

14. Coupland LA, Chong BH, Parish CR: Platelets and p-selectin control tumor cell metastasis in an organ-specific manner and independently of NK cells. Cancer Res 2012, 72(18):4662-4671.

15. Elboim M, Gazit R, Gur C, Ghadially H, Betser-Cohen G, Mandelboim O: Tumor immunoediting by NKp46. J Immunol 2010, 184:5637-5644.

16. Lakshmikanth T, Burke S, Ali TH, Kimpfler S, Ursini F, Ruggeri L, Capanni M, Umansky V, Paschen A, Sucker A, Pende D, Groh V, Biassoni R, Hoglund P, Kato M, Shibuya K, Schadendorf D, Anichini A, Ferrone S, Velardi A, Karre K, Shibuya A, Carbone E, Colucci F: NCRs and DNAM-1 mediate NK cell recognition and lysis of human and mouse melanoma cell lines in vitro and in vivo. J Clin Invest 2009, 119:1251-1263.

17. Moretta $L$, Moretta $A$ : Unravelling natural killer cell function: triggering and inhibitory human NK receptors. EMBO J 2004, 23:255-259.

18. Cerwenka A, Baron JL, Lanier LL: Ectopic expression of retinoic acid early inducible-1 gene (RAE-1) permits natural killer cell-mediated rejection of a MHC class I-bearing tumor in vivo. Proc Natl Acad Sci USA 2001, 98:11521-11526.

19. Diefenbach $A$, Jensen $E R$, Jamieson $A M$, Raulet $D H$ : Rae1 and $H 60$ ligands of the NKG2D receptor stimulate tumour immunity. Nature 2001, 413:165-171.

20. Ljunggren $\mathrm{HG}$, Malmberg $\mathrm{KJ}$ : Prospects for the use of NK cells in immunotherapy of human cancer. Nat Rev Immunol 2007, 7:329-339.

21. Tsukerman P, Stern-Ginossar N, Gur C, Glasner A, Nachmani D, Bauman Y, Yamin R, Vitenshtein A, Stanietsky N, Bar-Mag T, Lankry D, Mandelboim O: MiR-10b downregulates the stress-induced cell surface molecule MICB, a critical ligand for cancer cell recognition by natural killer cells. Cancer Res 2012, 72(21):1-10.

22. Armeanu S, Bitzer M, Lauer UM, Venturelli S, Pathil A, Krusch M, Kaiser S, Jobst J, Smirnow I, Wagner A, Steinle A, Salih HR: Natural killer cellmediated lysis of hepatoma cells via specific induction of NKG2D ligands by the histone deacetylase inhibitor sodium valproate. Cancer Res 2005, 65(14):6321-6329.

23. Butler JE, Moore MB, Presnell SR, Chan HW, Chalupny NJ, Lutz CT: Proteasome regulation of ULBP1 transcription. J Immunol 2009, 182:6600-6609.

24. Sutlu T, Alici E: Natural killer cell-based immunotherapy in cancer: current insights and future prospects. J Intern Med 2009, 266:154-181.

25. Wilson EB, El-Jawhari JJ, Neilson AL, Hall GD, Melcher AA, Meade JL: Human tumour immune evasion via TGF- $\beta$ blocks NK cell activation but not survival allowing therapeutic restoration of anti-tumour activity. PLoS One 2011, 6(9):e22842.

26. Clayton A, Mitchell JP, Court J, Linnane S, Mason MD, Tabi Z: Human tumor-derived exosomes down-modulate NKG2D expression. I Immunol 2008, 180:7249-7258.

27. Pietra G, Manzini C, Rivara S, Vitale M, Cantoni C, Petretto A, Balsamo M, Conte R, Benelli R, Minghelli S, Solari N, Gualco M, Queirolo P, Moretta L, Mingari MC: Melanoma cells inhibit natural killer cell function by modulating the expression of activating receptors and cytolytic activity. Cancer Res 2012, 72(6):1407-1415.

28. Buchser WJ, Laskow TC, Pavlik PJ, Lin HM, Lotze MT: Cell-mediated autophagy promotes cancer cell survival. Cancer Res 2012, $\backslash 72: 2970-2979$.

29. Balachandran VP, Cavnar MJ, Zeng S, Bamboat ZM, Ocuin LM, Obaid H, Sorenson EC, Popow R, Ariyan C, Rossi F, Besmer P, Guo T, Antonescu CR, Taguchi T, Yuan J, Wolchok JD, Allison JP, DeMatteo RP: Imatinib potentiates antitumor $\mathrm{T}$ cell responses in gastrointestinal stromal tumor through the inhibition of Ido. Nat Med 2011, 17(9):1094-1100.

30. Borg C, Terme M, Taieb J, Menard C, Flament C, Robert C, Maruyama K, Wakasugi H, Angevin E, Thielemans K, Le Cesne A, Chung-Scott V, Lazar V, Tchou I, Crepineau F, Lemoine F, Bernard J, Fletcher JA, Turhan A, Blay JY, Spatz A, Emile JF, Heinrich MC, Mecheri S, Tursz T, Zitvogel L: Novel mode of action of c-kit tyrosine kinase inhibitors leading to NK cell-dependent antitumor effects. J Clin Invest 2004, 114:379-388.

31. Alter G, Malenfant JM, Altfeld M: CD107a as a functional marker for the identification of natural killer cell activity. J Immunol Methods 2004, 294:15-22.

32. Hart OM, Athie-Morales V, O'Connor GM, Gardiner CM: TLR7/8-mediated activation of human NK cells results in accessory cell-dependent IFNgamma production. J Immunol 2005, 175:1636-1642. 
33. Nowbakht $P$, lonescu MC, Rohner $A$, Kalberer $C P$, Rossy $E$, Mori $L$, Cosman $D$, De Libero G, Wodnar-Filipowicz A: Ligands for natural killer cell-activating receptors are expressed upon the maturation of normal myelomonocytic cells but at low levels in acute myeloid leukemias. Blood 2005, 105:3615-3622.

34. Kim H, Kim SH, Kim MJ, Kim SJ, Park SJ, Chung JS, Bae JH, Kang CD: EGFR inhibitors enhanced the susceptibility to NK cell-mediated lysis of lung cancer cells. J Immunother 2011, 34:372-381.

35. Haura EB, Zheng Z, Song L, Cantor A, Bepler G: Activated epidermal growth factor receptor-Stat-3 signaling promotes tumor survival in vivo in non-small cell lung cancer. Clin Cancer Res 2005, 11:8288-8294.

36. Kim HP, Han SW, Kim SH, Im SA, Oh DY, Bang YJ, Kim TY: Combined lapatinib and cetuximab enhance cytotoxicity against gefitinib-resistant lung cancer cells. Mol Cancer Ther 2008, 7(3):607-615.

37. Ihara S, Kida H, Arase H, Tripathi LP, Chen YA, Kimura T, Yoshida M, Kashiwa Y, Hirata H, Fukamizu R, Inoue R, Hasegawa K, Goya S, Takahashi R, Minami T, Tsujino K, Suzuki M, Kohmo S, Inoue K, Nagatomo I, Takeda Y, Kijima T, Mizuguchi K, Tachibana I, Kumanogoh A: Inhibitory roles of signal transducer and activator of transcription 3 in antitumor immunity during carcinogen-induced lung tumorigenesis. Cancer Res 2012, 72(12):2990-2999.

38. Ramakrishnan R, Huang C, Cho HI, Lloyd M, Johnson J, Ren X, Altiok S, Sullivan D, Weber J, Celis E, Gabrilovich Dl: Autophagy induced by conventional chemotherapy mediates tumor cell sensitivity to immunotherapy. Cancer Res 2012, 72:5483-5493.

39. Carlsten M, Norell H, Bryceson YT, Poschke I, Schedvins K, Ljunggren HG, Kiessling R, Malmberg KJ: Primary human tumor cells expressing CD155 impair tumor targeting by down-regulating DNAM-1 on NK cells. J Immunol 2009, 183:4921-4930.

40. Hilpert J, Grosse-Hovest L, Grunebach F, Buechele C, Nuebling T, Raum T, Steinle A, Salih HR: Comprehensive analysis of NKG2D ligand expression and release in leukemia: implications for NKG2D-mediated NK cell responses. J Immunol 2012, 189:1360-1371.

41. Sutherland CL, Chalupny NJ, Schooley K, VandenBos T, Kubin M, Cosman D: UL16-binding proteins, novel MHC class I-related proteins, bind to NKG2D and activate multiple signaling pathways in primary NK cells. $\mathrm{J}$ Immunol 2002, 168:671-679.

42. Melero I, Hirschhorn-Cymerman D, Morales-Kastresana A, Sanmamed MF, Wolchok JD: Agonist antibodies to TNFR molecules that costimulate T and NK cells. Clin Cancer Res 2013, 19(5):1044-1053.

43. Kohrt HE, Houot R, Weiskopf K, Goldstein MJ, Scheeren F, Czerwinski D, Colevas AD, Weng WK, Clarke MF, Carlson RW, Stockdale FE, Mollick JA, Chen L, Levy R: Stimulation of natural killer cells with a CD137- specific antibody enhances trastuzumab efficacy in xenotransplant models of breast cancer. J Clin Invest 2012, 122(3):1066-1075.

44. Flaig RM, Stark S, Watzl C: Cutting edge: NTB-A activates NK cells via homophilic interaction. J Immunol 2004, 172(11):6524-6527.

45. Shibuya A, Campbell D, Hannum C, Yssel H, Franz-Bacon K, McClanahan T, Kitamura T, Nicholl J, Sutherland GR, Lanier LL, Phillips JH: DNAM-1, a novel adhesion molecule involved in the cytolytic function of T lymphocytes. Immunity 1996, 4(6):573-581.

46. Osaki T, Saito H, Yoshikawa T, Matsumoto S, Tatebe S, Tsujitani S, Ikeguchi M: Decreased NKG2D expression on CD8+ T cell is involved in immune evasion in patients with gastric cancer. Clin Cancer Res 2007, 13:382-387.

47. Kim SM, Kwon OJ, Hong YK, Kim JH, Solca F, Ha SJ, Soo RA, Christensen JG, Lee JH, Cho BC: Activation of IL-6R/JAK1/STAT3 signaling induces de novo resistance to irreversible EGFR inhibitors in non-small cell lung cancer with T790M resistance mutation. Mol Cancer Ther 2012, 11(10):2254-2264.

48. Sumpter TL, Dangi A, Matta BM, Huang C, Stolz DB, Vodovotz Y, Thomson AW, Gandhi CR: Hepatic stellate cells undermine the allostimulatory function of liver myeloid dendritic cells via STAT3-dependent induction of IDO. J Immunol 2012, 189:3848-3858.

\section{doi:10.1186/1479-5876-11-186}

Cite this article as: He et al:: Enhanced interaction between natural killer cells and lung cancer cells: involvement in

gefitinib-mediated immunoregulation. Journal of Translational Medicine 2013 11:186.

\section{Submit your next manuscript to BioMed Central and take full advantage of:}

- Convenient online submission

- Thorough peer review

- No space constraints or color figure charges

- Immediate publication on acceptance

- Inclusion in PubMed, CAS, Scopus and Google Scholar

- Research which is freely available for redistribution 